\title{
LONGITUDINAL CHANGES IN VENTRAL AND DORSAL NECK MUSCLE LAYERS DURING LOADING AGAINST GRAVITY IN HEALTHY VOLUNTEERS USING SPECKLE TRACKING
}

Anneli Peolsson and Michael Peolsson

\section{Linköping University Post Print}

\section{Tweet}

N.B.: When citing this work, cite the original article.

Original Publication:

Anneli Peolsson and Michael Peolsson, LONGITUDINAL CHANGES IN VENTRAL AND DORSAL NECK MUSCLE LAYERS DURING LOADING AGAINST GRAVITY IN HEALTHY VOLUNTEERS USING SPECKLE TRACKING, 2014, Journal of Manipulative and Physiological Therapeutics, (37), 4, 253-259.

http://dx.doi.org/10.1016/j.jmpt.2014.01.004

Copyright: Elsevier http://www.elsevier.com/

Postprint available at: Linköping University Electronic Press http://urn.kb.se/resolve?urn=urn:nbn:se:liu:diva-108176 


\section{TITLE PAGE}

\begin{tabular}{|c|c|}
\hline ARTICLE INFORMATION & Fill in information in each box below \\
\hline Article Title & $\begin{array}{l}\text { Longitudinal changes in ventral and dorsal neck muscle } \\
\text { layers during loading against gravity in healthy } \\
\text { volunteers using speckle tracking }\end{array}$ \\
\hline $\begin{array}{l}\text { Key Words - only use MeSH terms that are found at } \\
\text { http://www.nlm.nih.gov/mesh/meshhome.html }\end{array}$ & neck muscles; exercise; motor skills; ultrasonography \\
\hline Running head - no more than 40 letters/ spaces & Neck muscles mechanical activation during a head lift \\
\hline Word count for structured abstract (approx 250 words or less) & 185 \\
\hline Word count for text (excludes abstract, figure legends, references) & 2999 \\
\hline $\begin{array}{l}\text { Practical Applications } \\
\text { Three to } 5 \text { short sentences that highlight findings of the study. These } \\
\text { statements should relate directly to the study findings. }\end{array}$ & $\begin{array}{l}\text { The present results show the need for deep neck muscles } \\
\text { to act as neck stabilizers to resist gravity. } \\
\text { During this highly demanding exercise for the ventral } \\
\text { neck muscles, the sternocleidomastoid deformed more } \\
\text { than the deeper muscles but did it significantly slower } \\
\text { than the longus colli. } \\
\text { The dorsal neck muscles did not significantly differ in } \\
\text { deformation, however the multifidus had the highest } \\
\text { deformation rate. }\end{array}$ \\
\hline $\begin{array}{l}\text { Human Subjects and Animals } \\
\text { If human subject or animals were used, state the name of IRB, } \\
\text { Research Ethics Committee or equivalent in the Methods and here. }\end{array}$ & $\begin{array}{l}\text { All participants provided written informed consent. All } \\
\text { procedures were conducted according to the Declaration } \\
\text { of Helsinki, and the study was approved by the Ethics } \\
\text { Committee at the Faculty of Health Sciences at } \\
\text { Linköping University in Sweden. }\end{array}$ \\
\hline $\begin{array}{l}\text { Clinical Trial Registry } \\
\text { If the study was a clinical trial, please include clinical trial registration } \\
\text { number in the Methods and here. }\end{array}$ & N/A \\
\hline $\begin{array}{l}\text { Permission to Acknowledge } \\
\text { List the names of people who you are acknowledging and specifically } \\
\text { how they contributed to the study. A signed letter of permission from } \\
\text { each person and/or entity stating they give permission to the JMPT to } \\
\text { print their name must be uploaded to the website at the initial time of } \\
\text { submission. List permissions here. }\end{array}$ & N/A \\
\hline $\begin{array}{l}\text { Permission to reprint } \\
\text { If you are using any previously published figures or tables, a signed } \\
\text { letter of permission from the copyright holder stating they give } \\
\text { permission to the JMPT to reprint must be uploaded to the website at } \\
\text { the initial time of submission. List permissions here. }\end{array}$ & N/A \\
\hline $\begin{array}{l}\text { Funding sources } \\
\text { State funding sources (grants, funding sources, equipment, and } \\
\text { supplies). Include name and number of grant if available. Clearly } \\
\text { state if study received direct NIH or national funding. All sources of } \\
\text { funding should be acknowledged in the manuscript. }\end{array}$ & $\begin{array}{l}\text { Anneli Peolsson is supported by the Swedish Medical } \\
\text { Research Council and the Wenner-Gren foundations. }\end{array}$ \\
\hline
\end{tabular}




\section{Conflicts of interest}

List all potential conflicts of interest for all authors. Include those listed in the ICMJE form. These include financial, institutional and/or other relationships that might lead to bias or a conflict of interest. If there is no conflict of interest state none declared.

\section{Contributorship}

Concept development (provided idea for the research)

Design (planned the methods to generate the results)

Supervision (provided oversight, responsible for organization and

implementation, writing of the manuscript)

Data collection/processing (responsible for experiments, patient management organization, or reporting data)

Analysis/interpretation (responsible for statistical analysis, evaluation, and presentation of the results)

Literature search (performed the literature search)

Writing (responsible for writing a substantive part of the manuscript)

Critical review (revised manuscript for intellectual content, this does not relate to spelling and grammar checking)

Other (list other specific novel contributions)
The authors declare no conflicts of interests.

For each author, list initials for how the author contributed to this manuscript. List author initials for each relevant category

\section{AP, MP}

AP, MP
AP,$M P$
AP
AP
AP
AP, MP

$\mathrm{AP}, \mathrm{MP}$

\section{CORRESPONDING AUTHOR CONTACT INFORMATION}

\begin{tabular}{|l|l}
\hline $\begin{array}{l}\text { For the corresponding author (responsible for correspondence, } \\
\text { proofreading, and reprints) }\end{array}$ & A \\
\hline First name, middle initial, last name and degrees & A \\
\hline Email address - this is where your proofs will be sent \\
\hline $\begin{array}{l}\text { Postal mailing address - this is where your complimentary copy will be } \\
\text { shipped }\end{array}$ \\
\hline Phone number & \\
\hline Fax number & \\
\hline
\end{tabular}

Fill in information in each box below

Anneli Peolsson, Assoc. Prof., PhD, PT

Anneli.Peolsson@liu.se

Department of Medical and Health Sciences, physiotherapy,

Hälsans hus plan 12, Campus US, Linköping University, SE58183 Linköping

$+46-10-1031798$

$+46-10-1031706$

\section{First author}

First name, middle initial, last name of author. Include highest academic degree(s).

Title, academic or professional position (eg, Professor, University of Illinois) Name of department(s) and institution(s) to which work should be attributed for this author (eg, Kinesiology Department)

\section{Anneli Peolsson Assoc. Prof.}

Assoc. Prof., PhD, PT

NHMRC CCRE (Spinal Pain, Injury and Health), The University of Queensland, Brisbane, Australia; Department of Medical and Health Sciences, Division of Physiotherapy, Faculty of Health Sciences, Linköping University, Linköping, Sweden

\section{Second author}

First name, middle initial, last name of author. Include highest academic degree(s).

Title, academic or professional position (eg, Professor, University of Illinois) Name of department(s) and institution(s) to which work should be attributed for this author (eg, Kinesiology Department)

\section{Michael Peolsson Dr}

PhD, MSc CE, RN

Computational Life Science Cluster and Department of

Chemistry, Umeå University, Umeå, Sweden

\section{Third author}

First name, middle initial, last name of author. Include highest academic degree(s).

Title, academic or professional position (eg, Professor, University of Illinois)

Name of department(s) and institution(s) to which work should be attributed

for this author (eg, Kinesiology Department) 
Fourth author

First name, middle initial, last name of author. Include highest academic degree(s).

Title, academic or professional position (eg, Professor, University of Illinois)

Name of department(s) and institution(s) to which work should be attributed

for this author (eg, Kinesiology Department)

Fifth author

First name, middle initial, last name of author. Include highest academic

degree(s).

Title, academic or professional position (eg, Professor, University of Illinois)

Name of department(s) and institution(s) to which work should be attributed

for this author (eg, Kinesiology Department)

\section{Sixth author}

First name, middle initial, last name of author. Include highest academic degree(s).

Title, academic or professional position (eg, Professor, University of Illinois)

Name of department(s) and institution(s) to which work should be attributed

for this author (eg, Kinesiology Department)

(if there are additional authors, please copy, paste, then fill in)

JMPT/titlepageform/2013 
Neck muscles mechanical activation during a head lift

Longitudinal changes in ventral and dorsal neck muscle layers during loading against gravity in healthy volunteers using speckle tracking 
Neck muscles mechanical activation during a head lift

\begin{abstract}
Objectives: The present study aimed to describe and compare the longitudinal mechanical activity, deformation, and deformation rate of the different layers of dorsal and ventral neck muscles in healthy volunteers during head lifts against gravity.
\end{abstract}

Methods: The cross-sectional study included nineteen healthy volunteers (mean age, 28 years; SD, 7 years). Ultrasound with speckle-tracking analysis was used to investigate longitudinal mechanical activation, deformation, and deformation rate of dorsal and ventral neck muscles in real time during a head lift. Significance levels were set as $P=0.025$ or 0.0125 , depending on the number of comparisons.

Results: The dorsal neck muscles did not significantly differ in deformation $(P>0.04)$; however, the multifidus had a higher deformation rate than all other dorsal muscles $(P<$ 0.003). The sternocleidomastoid had significantly higher deformation than the longus capitis $(P=0.005)$ and colli $(P=0.001)$, but a lower deformation rate than the longus colli $(P=$ $0.02)$.

Conclusions: The sternocleidomastoid deformed more than the deeper muscles but did it significantly slower than the longus colli. Among the dorsal muscles, the deepest (the multifidus) had the highest deformation rate.

Keywords: neck muscles; exercise; motor skills; ultrasonography 


\section{INTRODUCTION}

Neck pain is a common problem, with published one-year prevalence ranging from 34$65 \%{ }^{1-4}$ and the highest values reported in the most recent reports. ${ }^{2,4}$ Neck muscles provide up to $80 \%$ of cervical spine stability. ${ }^{5}$ Compared with healthy subjects, people with neck pain show decreased neck muscle endurance ${ }^{6-8}$ and altered neck muscle activation patterns. ${ }^{9,}{ }^{10}$. In patients with neck disorders, neck-specific exercises are an important part of rehabilitation. ${ }^{11 \text {, }}$ 12

Training exercises and clinical tests of neck muscle endurance (NME) commonly utilize loaded and unloaded neck lift exercises against gravity, in prone positions for the extensors and in supine positions for the flexors. ${ }^{7,8,13,14,15}$ Only sparse information is currently available regarding which muscle layers are used in these positions without risk of cross talk. ${ }^{10,13,16,17}$ Several studies have analyzed post-performance muscle behavior by examining cross-sectional areas using magnetic resonance imaging (MRI) ${ }^{16}$ and functional MRI $(f M R I)^{10,13,17}$, and one has separately analyzed the behavioral functions of the longus capitis and longus colli. ${ }^{13}$ One disadvantage of $f$ MRI is that exercises cannot be studied in real time during the actual performance. No study has evaluated the different layers of neck muscles used and their mechanical properties in real time during exercise performance. Further investigations are needed to understand which muscles are actually activated and tested in measures of neck muscle endurance, which could be useful for improving rehabilitation protocols.

In the present study, healthy volunteers performed head lifts against gravity, and we used ultrasound imaging with speckle tracking to evaluate longitudinal changes of the neck muscles in real time. We aimed to investigate, describe, and compare the mechanical activity, deformation (percentage of change in longitudinal length), and deformation rate (the speed of 
Neck muscles mechanical activation during a head lift

the deformation) of the different layers of dorsal and ventral neck muscles during loading against gravity.

\section{METHODS}

\section{Participants.}

This cross-sectional study included nineteen healthy volunteers (10 women and 9 men; mean age, 28 years; SD, 7 years; range, $21-48$ years). Eighteen of the volunteers were right handed and one ambidextrous. Healthy was defined as follows: no present or past neck problems $\left[<10 \mathrm{~mm}\right.$ on the $\mathrm{VAS}^{18,19}$ and $<20 \%$ on the Neck Disability Index (NDI) ${ }^{20}$, no neck or head trauma, no rheumatological or neurological diseases, no generalized myalgia, and no severe back pain. The mean VAS value for pain intensity was $0.2 \mathrm{~mm}(\mathrm{SD}, 0.5$; range, 0-2), mean NDI score was $0.7 \%$ (SD, 0.8 ; range, $0-3$ ), and mean physical activity level was $3.9(\mathrm{SD}, 0.2$; range, $3-4)$ out of a maximum score of $4 . .^{15}$

All participants provided written informed consent. All procedures were conducted according to the Declaration of Helsinki, and the study was approved by the Ethics Committee at the Faculty of Health Sciences at Linköping University in Sweden.

\section{Ultrasound imaging.}

Anatomical assessments were performed with a $14.0 \mathrm{MHz}$ linear transducer (38-mm footprint) and an Ultrasound Vivid 9 Dimension (GE Healthcare, Horten, Norway) with a high frame rate (78 frames/s) operated in B-mode, and a 2D ultrasound imaging system. 
Neck muscles mechanical activation during a head lift

Images were recorded of the dorsal cervical muscles-including (from the most superficial to the deepest) the trapezius, splenius, semispinalis capitis, semispinalis cervicis, and multifidus (Fig. 1A). We also recorded images of ventral muscles, including the most superficial (sternocleidomastoid and longus capitis) and the deepest (longus colli) (Fig. 1B). For the dorsal muscles, an experienced physiotherapist identified the $\mathrm{C} 4$ level by palpation and marked the skin with a pen. The transducer was then positioned in a transverse orientation at that level on the right side, identifying the articular process, lamina, and the different layers of the dorsal neck muscles. For the ventral muscles, the transducer was positioned in a transverse orientation at the $\mathrm{C} 4$ level at the right side, using the bifurcation of the carotid artery and the thyroid as reference points to ensure imaging of the segmental level of interest. Once the operator was comfortable that the $\mathrm{C} 4$ spinal level had been identified, the transducer was rotated 90 degrees to a longitudinal orientation. This provided an optimal image plane for specialized post-process speckle-tracking analysis using research software based on the stable Farneback mathematical model. ${ }^{21}$

\section{Speckle-tracking analysis.}

When ultrasound waves hit irregularity in muscle tissues, they are reflected and spread out in different directions. When these sound waves meet each other, a unique acoustic mosaic pattern occurs (like ripples on the water when several stones have been thrown), which is like a fingerprint for that specific muscle. This unique speckle pattern could be analyzed using post-processing software to automatically identify the moving muscle structure of interest between the fascia during an exercise. Rectangular markers; region of interests (ROIs) $(10 \times 2 \mathrm{~mm})$ were manually placed along the fibers of each muscle during imaging to automatically tag and track the underlying muscle when moving. Each ROI 
Neck muscles mechanical activation during a head lift

contained hundreds of measuring points fixed to specific areas on the imaged muscle tissue, following and registering changes in the muscle's longitudinal length variation (contraction/elongation) frame-by-frame during the whole ultrasound movie sequence (AVIformat). When the muscle shortens, so does the ROI and vice versa. Median values for each measuring point were given for the specific ROI. Reliably ${ }^{14,21,22,23}$ and valid ${ }^{14}$ quantifying mechanical muscle activity by tracking the ROI in each and every frame is possible due to a speckle-tracking algorithm based on a stable mathematical model (Farneback). ${ }^{21}$ At least $80 \%$ agreement between frames is required to ensure that the muscle is consistently followed. Before analyzing the tracking using the software, the ROI was visually checked in slowmotion to ensure that it tagged and tracked the underlying muscle tissue of interest during the whole movie sequence.

We calculated two measurements of longitudinal muscle mechanical activity: deformation and deformation rate, with results presented as the root mean square (RMS). Muscle deformation (strain) was defined as the longitudinal change in muscle tissue during contraction (elongation/shortening during exercise) relative to a reference length (recorded pre-exercise in the first frame of the video). Muscle deformation during exercise was expressed as a percentage of the pre-exercise muscle length (\% strain). Muscle deformation rate (\% strain $1 / \mathrm{s})$ was defined as the deformation per time unit, and provided information concerning the speed of the longitudinal muscle deformation.

Test procedure of dorsal and ventral neck muscles.

The test procedure was standardized ${ }^{8,15}$ and carefully monitored by the test leader. Before the test, the participants were instructed in the test performance, and a test trial was performed in each position to ensure understanding. The participants were instructed to lift on 
Neck muscles mechanical activation during a head lift

"lift," after the test leader had counted to three; to maintain the test position for $5 \mathrm{~s}$; and on "down," to lower their head for rest. Ultrasound recordings were taken from "lift" to "down," with ultrasound videos of about 7-seconds long.

When measuring the dorsal neck muscles, the participant was in a prone position with legs straight, arms positioned at the sides, and a load ( $2 \mathrm{~kg}$ for women and $4 \mathrm{~kg}$ for men) applied around the head just above the ears. The participant then extended and raised the head just above the examination table, with the tip of the chin pointing against the floor ${ }^{8,15}$ (Fig. 2A).

When ventral NME was measured, the subject was in a supine position with legs straight and the arms positioned alongside the body. The subject was instructed to flex the upper cervical spine, and was told "do a small nod of the head, hold your chin against your chest, and raise your head just above the examination table" ${ }^{\mathrm{8}, 15}$ (Fig. 2B).

\section{Statistical methods.}

Data was reported using descriptive statistics with mean and standard deviation (SD). General linear model repeated measures analysis was used to determine the main effect of a muscle. Deformation was analyzed based on the area over (elongation relative to the length of the first frame of the video) and under (relative contraction) the curve line of zero (no deformation). For tests of simple effects, repeated measure analysis of variance (ANOVA) with the Bonferroni post-hoc test was used for comparisons of both deformation and deformation rates between muscle layers. For ventral and dorsal neck muscles, respectively, $P$-values of $\leq 0.025$ and $\leq 0.0125$ were considered significant. The ventral/dorsal ratio was 
Neck muscles mechanical activation during a head lift

calculated by dividing the mean values of the deformation results of all ventral neck muscles by the mean of all the dorsal neck muscles.

\section{RESULTS}

Table 1 presents patient descriptive statistics.

\section{Dorsal neck muscles.}

Muscle type had no main effect on deformation $(P=0.32)$. Tests of simple effects showed that, although the multifidus had the highest mean deformation value, there were no significant differences between the deformation values among dorsal neck muscles $(P>$ 0.04). The semispinalis cervicis had a larger area under the zero line (relative shortening) compared with the splenius $(P=0.009)$. There was also a tendency for the multifidus to have a larger area under the zero line than the semispinalis cervicis $(P<0.02)$. The muscles did not significantly differ in the areas over the zero line (relative elongation) $(P>0.13)$.

There was a main effect of muscle type on deformation rate $(P=0.01)$. Tests of simple effects showed that the multifidus had a higher deformation rate than all the other dorsal muscles $(P<0.003)$.

\section{Ventral neck muscles.}

For ventral neck muscles, muscle type had a significant main effect on deformation $(P$ $=0.003)$. Tests of simple effects showed that the sternocleidomastoid had significantly higher 
Neck muscles mechanical activation during a head lift

deformation than both the longus capitis $(P=0.005)$ and colli $(P=0.001)$. When the deformation was split into the separate areas over (relative elongation) and under (relative shortening) the zero line, no differences were observed between the muscles for the area over the line $(P>0.37)$. For area under the line (relative shortening), the sternocleidomastoid had a significant larger area than the longus colli $(P=0.008)$.

Muscle type had no significant main effect on deformation rate $(P=0.08)$, but tests of simple effects showed that the sternocleidomastoid had a lower deformation rate than the longus colli $(P=0.02)$.

Ratio.

The ventral/dorsal ratio was 2.7 (SD, 2.50), showing that the NME test placed a higher demand on the ventral neck muscles than the dorsal ones.

\section{DISCUSSION}

Dorsal neck muscles.

The present data showed a trend of the deepest dorsal neck muscles (the multifidus) having higher mean deformation values, due to greater shortening relative to the other dorsal neck muscles. However, the data showed large variation and thus no significant differences in deformation between the dorsal muscles. The observed trend of high activation in deep muscles corresponds well with previous results obtained from $\mathrm{MRI}^{16}$ and $f \mathrm{MRI}^{17}$ of the extensor muscles when activated in the prone position. Conley et al. ${ }^{16}$ found relatively less use (change in cross-sectional area) of the trapezius, and marked use of the semispinalis and 
Neck muscles mechanical activation during a head lift

multifidus muscles, while Elliott et al. ${ }^{17}$ reported increased T2 shifts in the semispinalis and multifidus muscles compared to in the splenius during the head lift.

The multifidus had a significantly higher deformation rate compared to all other muscles. This finding indicates that the deep multifidus muscle was highly active, stabilizing the cervical spine when lifting against gravity, and therefore that the multifidus is active when exercising or testing endurance in the investigated position.

\section{Ventral neck muscles.}

Among the ventral muscles, the most superficial muscle (the sternocleidomastoid) had the greatest deformation but the lowest deformation rate. Results from earlier studies are contradictory. ${ }^{13,16,24}$ During cervical flexion and during cervical flexion combined with craniocervical flexion during head lifts in the supine position, Cagnie et al. (13) reported significant T2 increases on $f$ MRI for the sternocleidomastoid, longus capitis, and longus colli; these findings show that these muscles are active during head lifts in the supine position, which is in line with the results of the present study. However, they ${ }^{13}$ also found that, during the cervical flexion exercise, the longus capitis had a significantly higher $\mathrm{T} 2$ increase than the longus colli and sternocleidomastoid, and they observed higher T2 increases in both the longus capitis and colli compared with the sternocleidomastoid. These results are contradictory to our present findings and to those of Conley et al. ${ }^{16}$ and O'Leary et al., ${ }^{24}$ in which the sternocleidomastoid showed the highest activity during the cervical flexion task against gravity. These different results may be due to differences in the test performance, or to the use of different measurement methods. Although both $f$ MRI results and deformation values obtained from speckle tracking have shown a relationship with electrical muscle activity, ${ }^{14,25}$ and speckle tracking results also show a linear relationship with maximal 
Neck muscles mechanical activation during a head lift

voluntarily contraction, ${ }^{14}$ results from the two methods cannot be equalized as the degree of force used.

Although they showed lower deformation than the sternocleidomastoid, the deep ventral muscles had higher deformation rates. This finding shows the ability of these deep muscles to stabilize the cervical spine during the performance of small involuntarily directional movement changes, as the participant tried to hold the head still during the relatively heavy task.

\section{Ratio between ventral and dorsal neck muscles.}

There may be a number of reasons for our finding that the most superficial muscle had the lowest deformation for the dorsal neck muscles but the highest deformation for the ventral muscles. The ratio between the ventral and dorsal neck muscles shows that the head lift placed a higher demand on the ventral muscles than the dorsal muscles. The long flexion moment arm of the superficial sternocleidomastoid muscle may give it a biomechanical advantage for force development compared with the deep postural and stabilizing muscles ${ }^{26}$; the sternocleidomastoid underwent more than twice the deformation of the trapezius during the low-demanding task in extension. The determined ratio is logical and in line with the findings of other studies in both healthy patients and neck pain patients. ${ }^{8,15}$

The lower deformation of the deep ventral neck muscles compared with in the sternocleidomastoid may also be due to the test procedure when the head lift was registered. As the participant was instructed to perform a craniocervical flexion prior to the lift, the deep ventral neck muscles may have already been highly activated before the lift and thereby before registration started. Since the deformation was a measure of the percentage of change 
Neck muscles mechanical activation during a head lift

in deformation compared with the first image in the video sequence, this procedure may have influenced the results and led to false too-low deformation values for the deep ventral flexors. To specifically evaluate the deep ventral neck flexors in a clinical situation, the head lift is not considered optimal and other less-demanding strategies are needed. ${ }^{27}$

\section{Limitations of the study.}

Technical limitations of ultrasound registrations did not allow recording the sequence to exhaustion; we could only evaluate the first few seconds when the subject was taking the position. The muscles may act differently later in the endurance test; therefore, although the present study is important, it should be viewed as only a first step in investigating muscle activation during the examined positions. The neck muscle response depends on the exercise performed and the load used and can't be extrapolated to other exercises. The population in the present study was relatively young and well exercised. No altered muscle sizes of deep neck muscles have been found by age ${ }^{28}$ and most participants reported training such as jogging without specific neck exercises, which suggest the data collected to be representative of healthy adult neck muscles.

Furthermore, the muscles were only recorded at the $\mathrm{C} 4$ segmental level, and may have been acting different at other segmental levels. Additionally, the present study only included healthy volunteers, but muscle activity reorganization is to be expected in people with pain. ${ }^{29-}$

${ }^{31}$ Future studies should include patients with neck pain, for comparison with healthy subjects. It would also be beneficial to have a larger study sample; however, as with other imaging analyses, the process was very time consuming. 
Another limitation is that the ultrasound image is two-dimensional, measuring the longitudinal movements but unable to capture rotational movements as muscles move threedimensionally. Variations in anatomical architecture and positions on the skeleton, could also mean that the muscles were imaged in slightly different planes. These facts along with varying muscle lengths may have influenced the imaging analysis results, and cannot be controlled for using the present technique. The advantage with the methodology used is that it is a safe non-invasive technique with the ability to do measurements in real time during a movement and to during analysis watch the muscles during the entire exercise to ensure that the ROI remained tagged.

The magnitude of muscle deformation (obtained with Speckle Tracking Analysis) and the magnitude of muscle activity using other measurements (force, progressive electrical stimulation) are related, providing justification for the use of the measurements performed in this study. ${ }^{14}$ However, it is not straightforward to equalize muscle deformation with strength.

\section{Clinical implications.}

It is important to understand which muscles are actually activated and tested in measures of and when training neck muscle endurance. As previously reported, ${ }^{13,15}$ the ventral head lift was highly demanding, as reflected by our finding that the most superficial of the ventral neck muscles (the sternocleidomastoid) had the highest deformation. In contrast, we observed no significant differences between the different muscle layers in the dorsal neck muscles, but there was a clear trend that the deepest investigated muscle (the multifidus) had the highest deformation. For both directions, the deformation rate was highest in the deep muscles, indicating that they are activated to stabilize the cervical spine when 
Neck muscles mechanical activation during a head lift

lifting against gravity. These findings indicate that, in clinical practice, one should be aware that all neck muscle layers are trained/ exercised with different functions; that the ventral test is highly demanding and involves great sternocleidomastoid activation; and that the extensor position is favorable for the multifidus muscle, despite external loadings.

\section{Conclusions}

Our results indicate that all layers of both the dorsal and ventral neck muscles were active but working somewhat differently. The sternocleidomastoid deformed more than the deeper muscles, but deformed significantly more slowly than the longus colli muscle. Among the dorsal muscles, it was also the deepest (the multifidus) that showed the highest deformation rate.

\section{REFERENCES}

1. Bovim G, Schrader H, Sand T. Neck pain in the general population. Spine 1994;19:13079.

2. Chiu TT, Leung AS, Lam P. Neck pain in Hong Kong: a telephone survey on consequences and health service utilization. Spine 2010;35:E1088-95.

3. Linton SJ, Hellsing AL, Halldén K. A population-based study of spinal pain among 35-45year-old individuals. Prevalence, sick leave, and health care use. Spine 1998;23:1457-63. 
Neck muscles mechanical activation during a head lift

4. Niemeläinen R, Videman T, Battié MC. Prevalence and characteristics of upper or midback pain in Finnish men. Spine 2006;31:1846-96.

5. Panjabi MM, Cholewicki J, Nibu K, Grauer J, Babat LB, Dvorak J. Critical load of the human cervical spine: an in vitro experimental study. Clin Biomech 1998;13:11-7.

6. Jordan A, Mehlsen J, Ostergaard K. A comparison of physical characteristics between patients seeking treatment for neck pain and age-matched healthy people. J Manipulative Physiol Ther 1997;20:468-75.

7. Lee H, Nicholson LL; Adams RD. Neck muscle endurance, self-report and range of motion data from subjects with treated and untreated neck pain. J Manipulative Physiol Ther $2005 ; 28: 25-32$.

8. Peolsson A, Kjellman G. Neck muscle endurance in non-specific neck-pain patients and in patients after anterior cervical decompression and fusion. J Manip Physiol Ther 2007;30: $343-50$.

9. Falla D, Bilenkij G, Jull G. Patients with chronic neck pain demonstrate altered patterns of muscle activation during performance of a functional upper limb task. Spine 2004;29:143640.

10. O’Leary S, Cagnie B, Reeve A, Jull G, Elliott JM. Is there altered activity of the extensor muscles in chronic mechanical neck pain? A functional magnetic resonance imaging study. Arch Phys Med Rehabil 2011;92:929-34.

11. Kay TM, Gross A, Goldsmith C, Santaguida PL, Hoving J, Bronfort G; Cervical Overview Group. Exercises for mechanical neck disorders. Cochrane Database Syst Rev Jul 2005;20:(3):CD004250. 
Neck muscles mechanical activation during a head lift

12. Kay TM, Gross A, Goldsmith CH, Rutherford S, Voth S, Hoving JL, Brønfort G, Santaguida PL. Exercises for mechanical neck disorders. Cochrane Database Syst Rev Aug 2012;15:8:CD004250.

13. Cagnie B, Dickx N, Peeters I, Tuytens J, Achten E, Cambier D, Danneels L. The use of functional MRI to evaluate cervical flexor activity during different cervical flexion exercises. J Appl Physiol 2008;104:230-5.

14. Lopata RG, van Dijk JP, Pillen S, Nillesen MM, Maas H, Thijssen JM Stegeman DF, de Korte CL. Dynamic imaging of skeletal muscle contraction in three orthogonal directions. J Appl Physiol 2010;109: 906-15.

15. Peolsson A, Almkvist C, Dahlberg C, Lindqvist S, Pettersson S. Age- and sex-specific reference values of a test of neck muscle endurance. J Manip Physiol Ther 2007;30:171-7.

16. Conley MS, Meyer RA, Bloomberg JJ; Feeback DL, Dudley GA. Noninvasive analysis of human neck muscle function. Spine 1995;20:2505-12.

17. Elliott JM, O’Leary SP, Cagnie B, Durbridge G, Danneels L, Jull G. Caraniocervical orientation affects muscle activation when exercising the cervical extensors in healthy subjects. Arch Phys Med Rehabil 2010;91:1418-22.

18. Croft PR, Macfarlane GJ, Papageorgiou AC, Thomas E, Silman AJ. Outcome of low back pain in general practice: a prospective study. BMJ 1998;316:1356-9.

19. Scott J, Huskisson EC. Graphic representation of pain. Pain 1976;2:175-84.

20. Vernon H, Mior S. The neck disability index: a study of reliability and validity. J Manip Physiol Ther 1991;14:409-15. 
Neck muscles mechanical activation during a head lift

21. Peolsson M, Löfstedt T, Vogt S, Stenlund H, Arndt A, Trygg J. Modelling human musculoskeletal functional movements using ultrasound imaging. BMC Med Imaging 2010;10:9.

22. Arndt A, Bengtsson AS, Peolsson M, Thorstensson A, Movin T. Nonuniform displacement within the Achilles tendon during passive ankle joint motion. Knee Surg Sports Traumatol Arthrosc 2012;20:1868-74.

23. Peolsson A, Löfstedt T, Trygg J, Peolsson M. Ultrasound imaging with speckle tracking of cervical muscle deformation and deformation rate: isometric contraction of patients after anterior cervical decompression and fusion for cervical disc disease and controls. Man Ther 2012;17:519-525.

24. O’Leary S, Falla D, Jull G, Vicenzino B. Muscle specificity in tests of cervical flexor muscle performance. J Electromyogr Kinesiol 2007;17:35-40.

25. Dickx N, D'Hooge R, Cagnie B, Deschepper E, Verstraete K, Danneels L. Magnetic resonance imaging and electromyography to measure lumbar back muscle activity. Spine 2010;35:E836-42.

26. Vasavada AN, Li S, Delp SL. Influence of muscle morphometry and moment arms on the moment-generating capacity of human neck muscles. Spine 1998;23:412-22.

27. Jull GA, O'Leary SP, Falla DL. Clinical assessment of the deep cervical flexor muscles: the craniocervical flexion test. J Manipulative Physiol Ther 2008;31:525-33.

28. Rankin G, Stokes M, Newham DJ. Size and shape of the posterior neck muscles measured by ultrasound imaging: normal values in males and females of different ages. Man Ther 2005;10:108-15. 
Neck muscles mechanical activation during a head lift

29. Cagnie B, Dirks R, Schouten M, Parlevliet T, Cambier D, Danneels L. Functional reorganization of cervical flexor activity because of induced muscle pain evaluated by muscle functional magnetic resonance imaging. Man Ther 2011;16:470-5.

30. Cagnie B, O’Leary S, Elliott J, Peeters I, Parlevliet T, Danneels L. Pain-induced changes in the activity of the cervical extensor muscles evaluated by muscle functional magnetic resonance imaging. Clin J Pain 2011;27:392-7.

31. Falla D, Farina D. Neuromuscular adaptation in experimental and clinical neck pain. J Electromyogr Kinesiol 2008;18:255-61. 
Neck muscles mechanical activation during a head lift

Table 1. Deformation and deformation rate (mean (SD)) of dorsal and ventral neck muscles in root mean square (RMS) during a head lift from the examination table.

\section{Deformation Deformation rate}

\begin{tabular}{lll}
\hline Trapezius & $4.81(3.87)$ & $0.007(0.003)$ \\
Splenius & $6.14(4.47)$ & $0.011(0.006)$ \\
Semispinalis capitis & $5.97(4.50)$ & $0.013(0.010)$ \\
Semispinalis cervicis & $5.37(3.13)$ & $0.015(0.012)$ \\
Multifidus & & \\
Sternocleidomastoid & $11.76(8.41)$ & $0.024(0.011)$ \\
Longus capitis & $7.12(7.85)$ & $0.027(0.019)$ \\
Longus colli & $6.31(4.02)$ & $0.031(0.021)$ \\
\hline
\end{tabular}




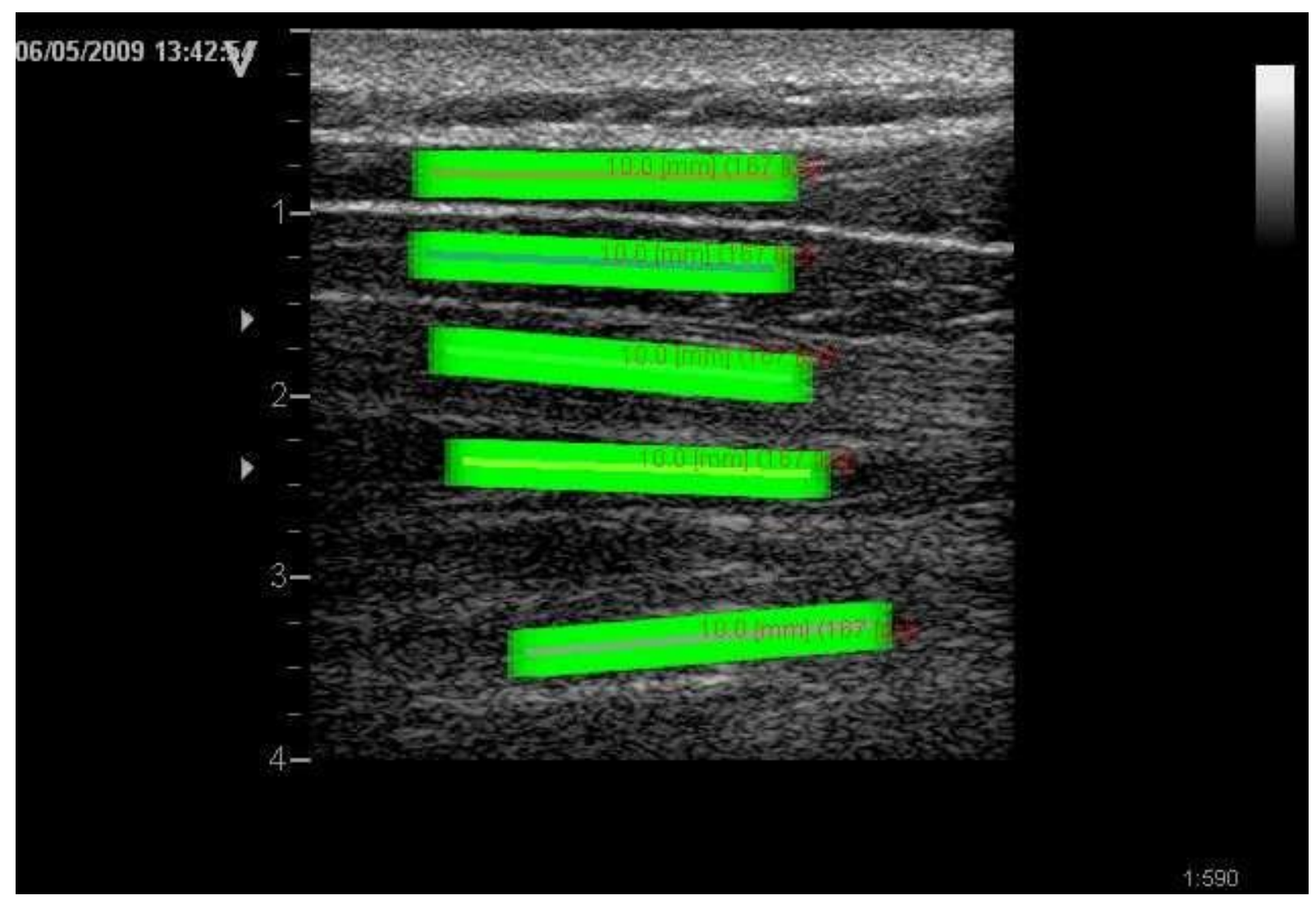

Fig. 1A

Longitudinal ultrasound projection of the dorsal neck muscles with ROI added on top of the muscle imaging. The following muscles were included (from most superficial to deepest): trapezius, splenius capitis, semispinalis capitis, semispinalis cervicis, and multifidus. 


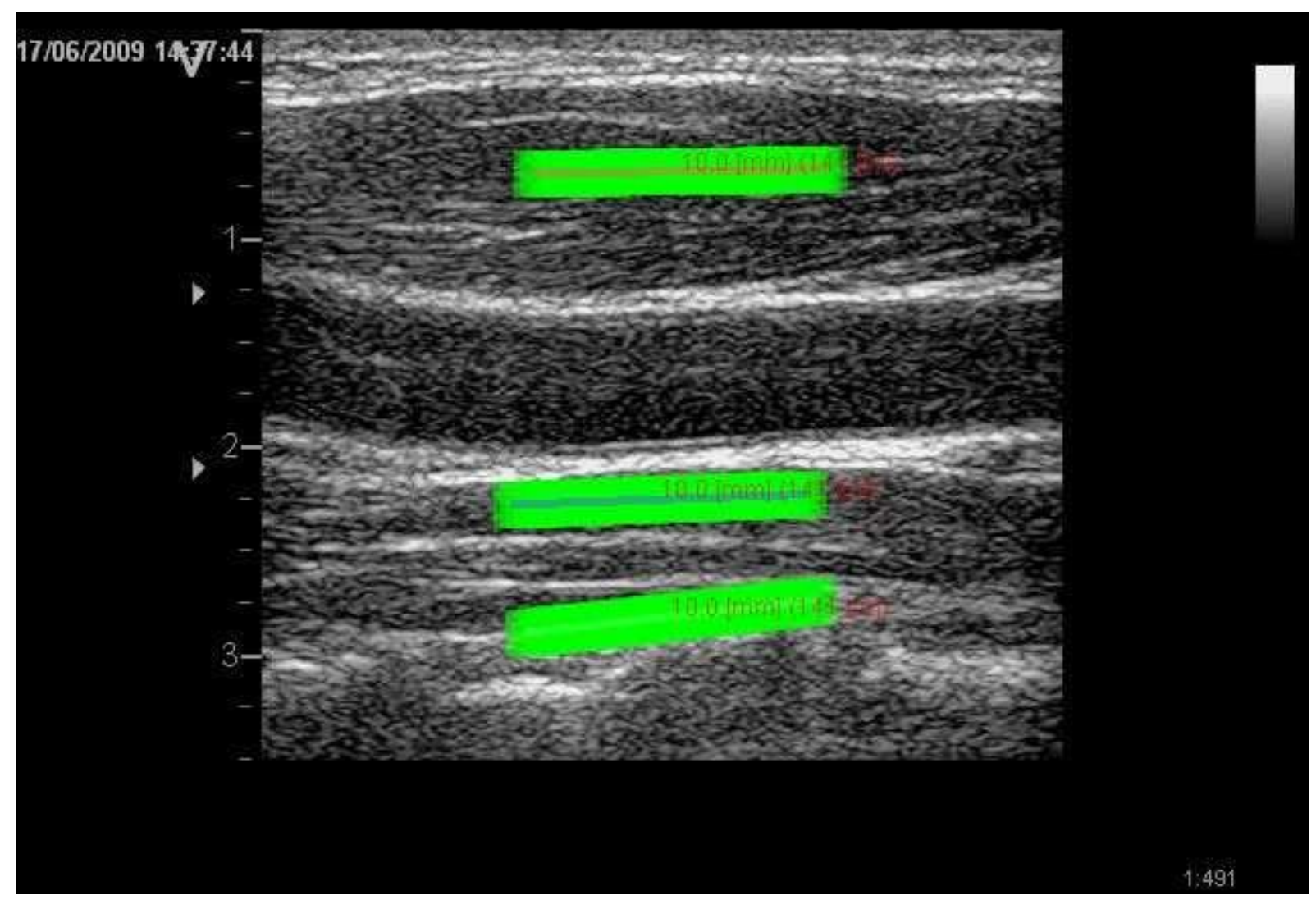

Fig. 1B

Longitudinal ultrasound projection of the ventral neck muscles with ROI added on top of the muscle imaging. The following muscles were included (from most superficial to deepest): sternocleidomastoid, longus capitis, and longus colli. 


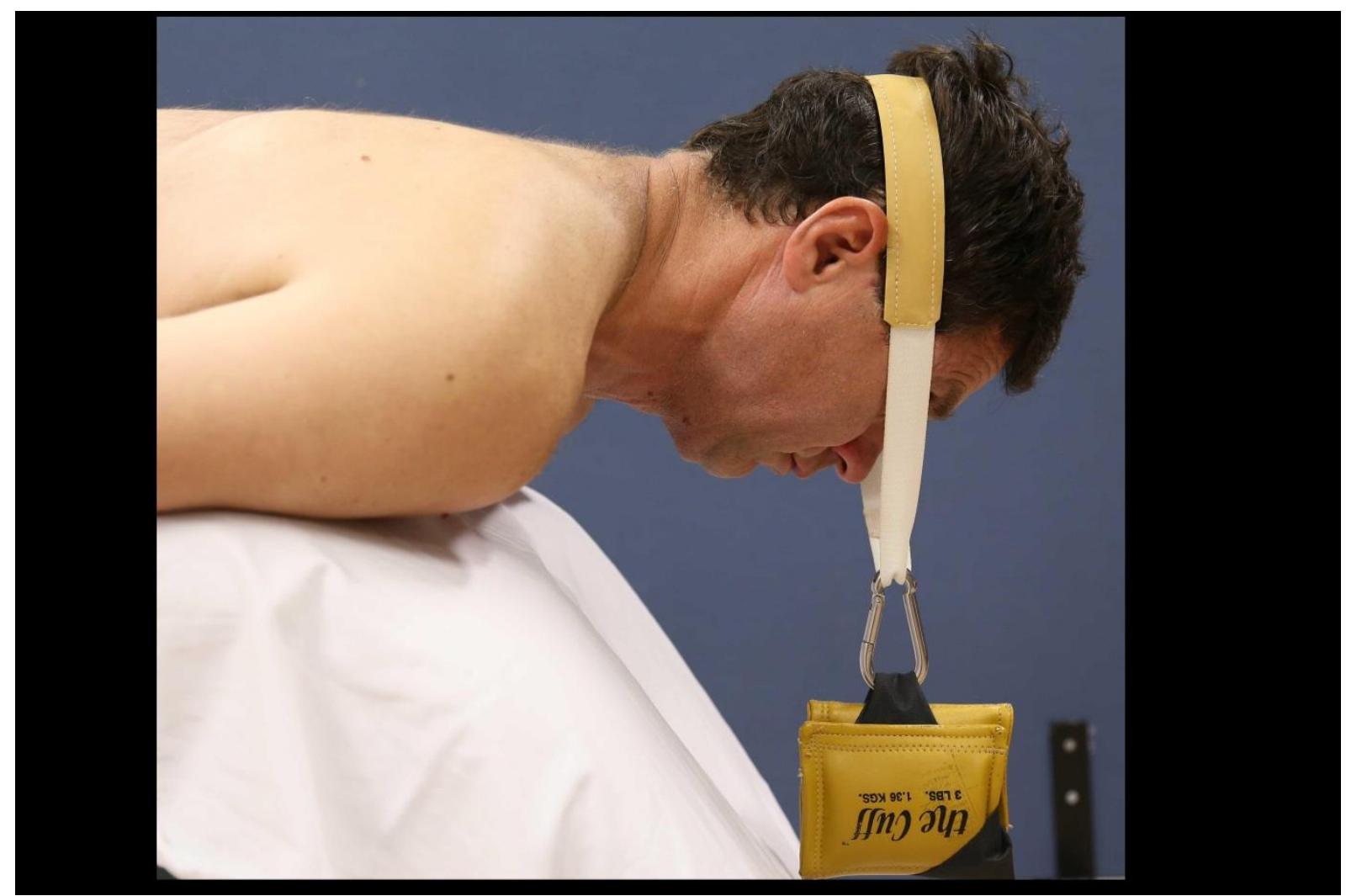

Fig. 2A

Position for the ultrasound recording of the dorsal neck muscles. During ultrasound measurements, the examination table was in a horizontal position. In this photo, the head of the table was tipped to make the headband and weight visible. 


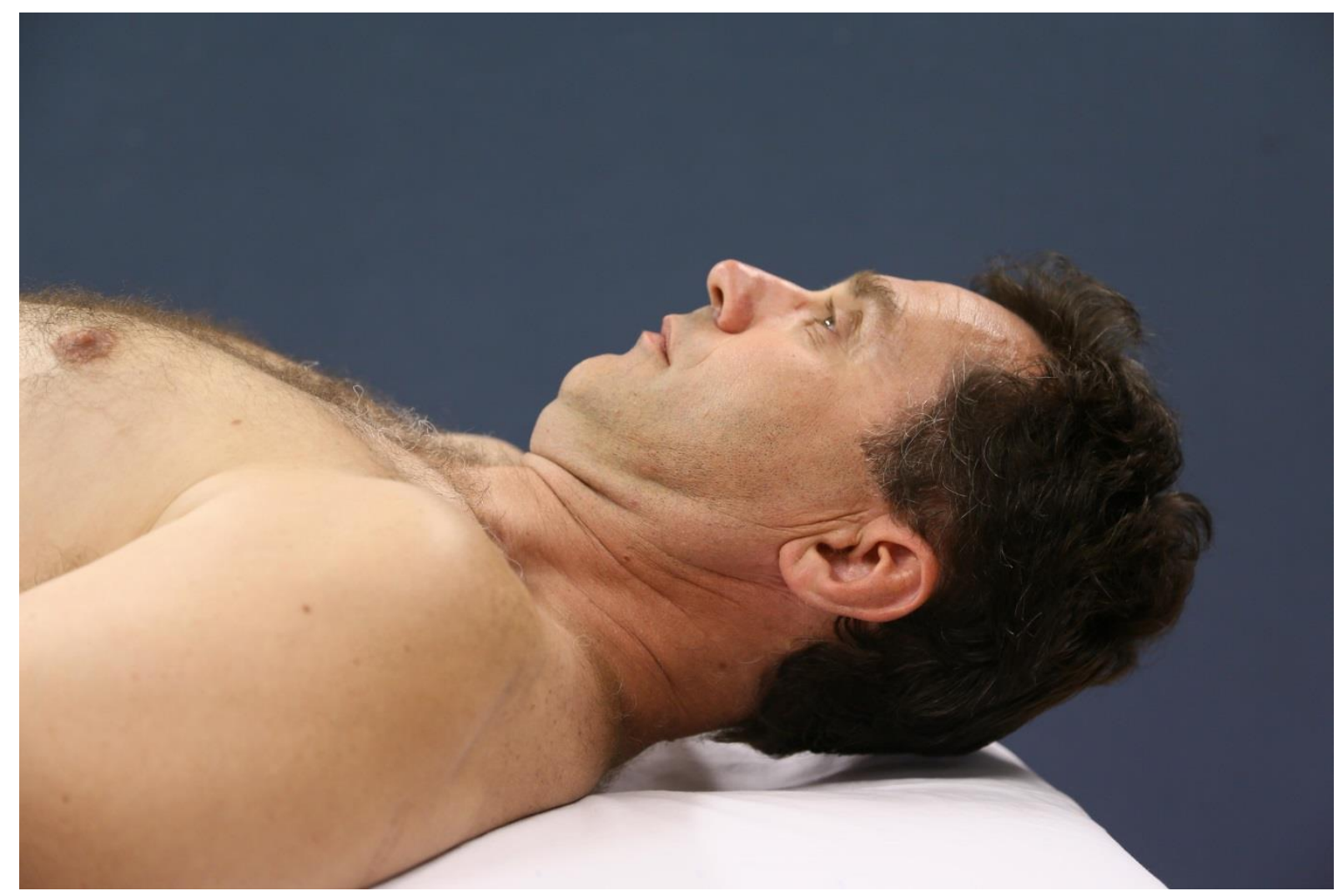

Fig. 2B

Position for the ultrasound recording of the ventral neck muscles. 